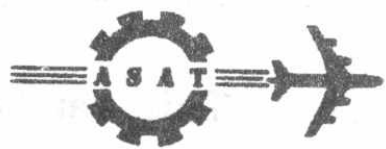

$7^{\text {th }}$ INTERNATIONAL CONF. ON AEROSPACE SCIENCES \& AVIATION TECHNOLOGY

\title{
A TEST RIG FOR DYNAMIC EVALUATION OF OFF - ROAD
}

\section{TIRES CHARACTERISTICS}

\author{
Yehia H. Hossamel-deen (Ph.D)*, Mohamed A. El-Haddad (Ph.D.)**, \& \\ Eng. Shawky A. Hegazy** \\ * Higher Technological Institute (H.T.I); Sixth of October City \\ ** Automotive Engineering Department, Military Technical College (MTC)
}

\begin{abstract}
:
In order to evaluate the tire - vehicle - terrain system, the tire- road characteristics should be determined carefully. This needs theoretical model and / or practical testing under controlled environment which can be fulfilled using a soil bin. Before this work, such facility did not exist in Egypt. Accordingly; the objective of this work was set to design, produce, and assemble a test rig for dynamic evaluation of off-road tire characteristics (soil bin). The constructed soil bin mainly consists of a single driven tire traction tester, towing resistance, measuring equipment, and testing track containing the tested soil. The measured data (the input driving torque, the net traction, the sinkage, and the tire revolutions) can be recorded on a digital data acquisition system and processed using a computer.
\end{abstract}

Key Words : Tires Characteristics - Soil Bin - Road Tire interaction.

\section{INTRODUCTION:}

The mobility of vehicles on off-roads depends mainly on engine power and matching of tire and soil characteristics. The tire'-road adhesion limits the engine power which can be used for vehicle driving. In order to fully utilise the available tire - road adhesion, all wheel drive is used. However; in some cases, all wheel drive scheme may result in what is so called kinematics discrepancy. This discrepancy causes over stress on axle shafts and excessive tire wear, especially when the vehicle is not equipped with interaxle differential.

In order to analyse the tire - road adhesion characteristics; tire-terrain simulation and / or tire - terrain testing are required. The tire testing may be static or dynamic, and it can be obtained either in field or in laboratory. The field testing may give the nearest result for the actual conditions, but the effect of driver, and the uncontrolled change of environmental conditions may greatly affect the accuracy of the results. Using a soil bin in which the field conditions are simulated under controlled conditions may give a suitable solution to have accurate results under controlled observation in conditions similar to the field ones. For this objective a soil bin is constructed in the Automotive Engineering Department, Military Technical College. This soil bin mainly consists of a single driven tire traction, towing resistance, measuring equipment, and testing track containing the tested soil. The measured values ( the driving torque, net traction, sinkage, and the tire revolutions) can be recorded on a digital data acquisition system and processed using the computer. From the measured data, the tire - road slip characteristics, drawbar pull - slip characteristics, and dynamic sinkage 
versus load can be evaluated. This can be used for tire - vehicle - terrain system study.

2. DESIGNED SOIL BIN:

A soil bin is designed and produced in the Automotive Engineering Department, Military Technical College , Fig. 1. It mainly consists of:-

2.1 Single tire traction tester.

2.2 The measuring equipment and data acquisition .

2.3 The testing track.

2.4 The control room .

In this section a brief description of the constructed soil bin is to be highlighted.

2.1 Single Tire Traction Tester:

The single tire traction tester contains the tested tire driven through an electric motor via transmission system on a testing track of $20 \mathrm{~m}$ length which contains the tested soil. The tester is equipped with different equipment to measure the tested tire driving torque, its number of revolution sinkage. Also contain a data acquist which is then processed by a computer transducer into its internal The main components of the single wheel traction using a special soft wig.2:
tester are shown in Fig.

a-Frame:

The frame is a load carrying beam structure consisting of two longitudinal beams, with $U$ cross sectional type, and several cross members. The frame is the base to which all main parts and units are assembled. The length of the frame is $2.45 \mathrm{~m}$, and its width is $0.52 \mathrm{~m}$, It also includes the following :

- Two rigid wheels, used to guide the vehicle on the ranted to troel is assembled on a shaft with 2 bearings, the shaft is mounted to transverse assembled on a shaft with 2 bearings, the shaft is miche frame. The rigid
beam with screw and nuts which carries the vehiclentre of gravity for
wheels are permanently guided by the rails. The centre the traction tester, lies directly above the wheel 's shaft .

- Two side caster wheels in the right and left sides of vehicle for guidance inside the testing track side walls.

b. Driving System: The driving system consists meller shaft, final drive, wheel hub with its shaft, mechanical gear box, a propelts of the driving system are chosen to withstand the forces under which the tire is tested.

- Electric motor:

The electric motor is an AC motor of $22 \mathrm{~kW}$ maximum power at speed of $1460 \mathrm{rpm}$. Its frequency range is from 30 to $50 \mathrm{~Hz}$.

- Mechanical gear box : 4 forward speed gear ratios and a reverse is A mechanical gearbox with 4 the forward speeds are : 6.4, 3.09, 1.69, 1 and the reverse speed ratio is 7.82 . 


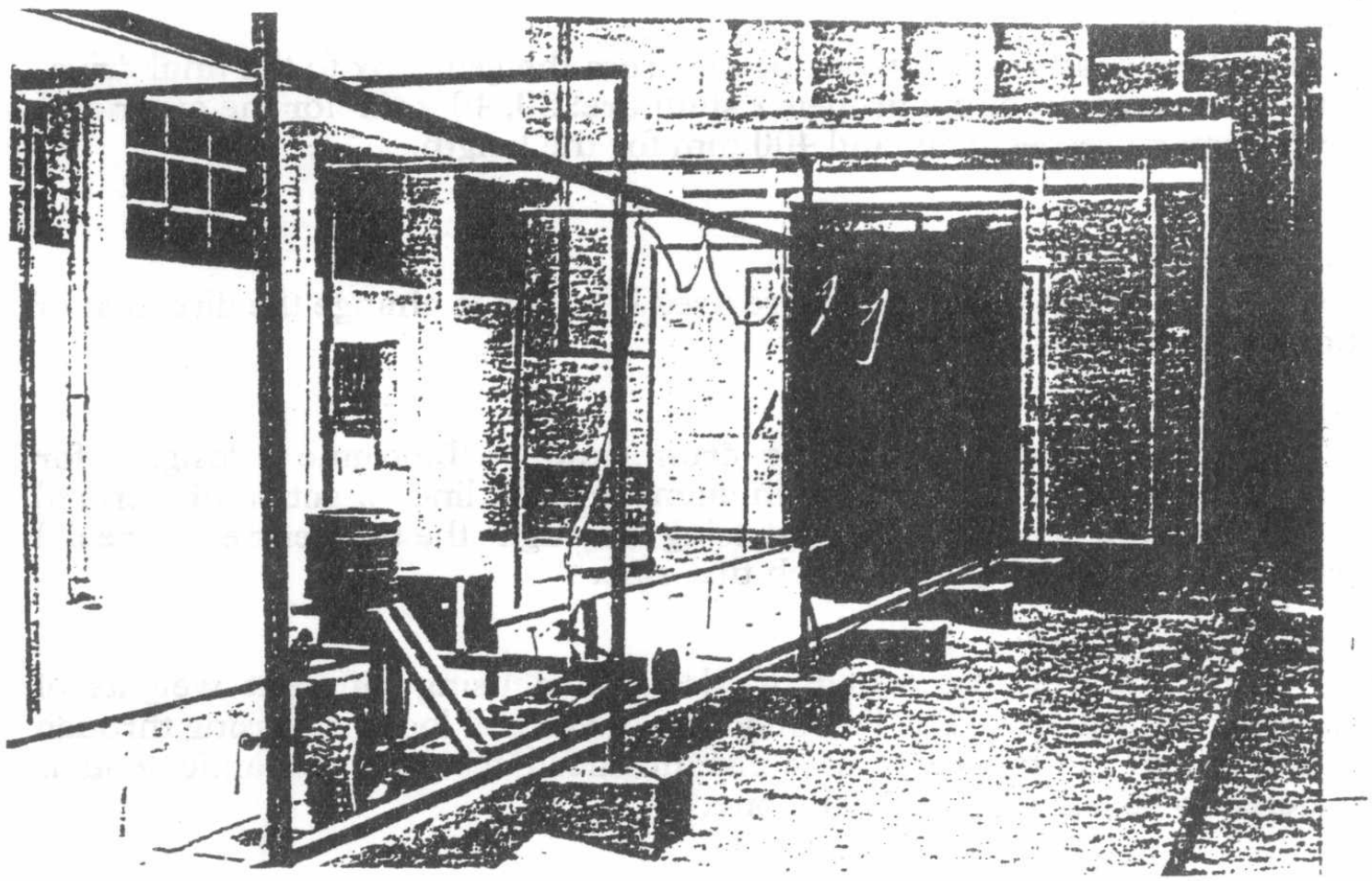

Fig. I View of soil bin

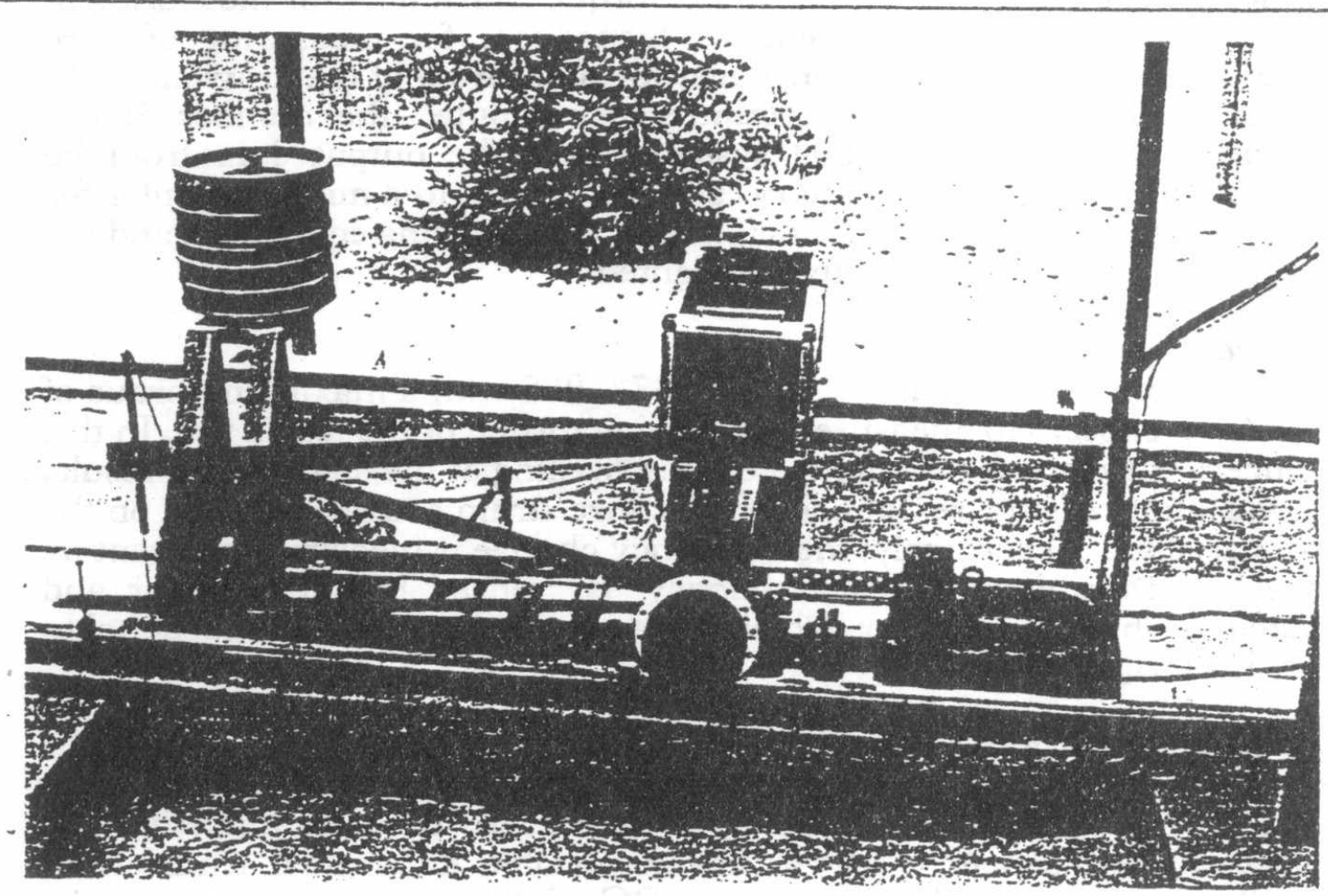

Fig. 2 Single tire traction tester 
-Propeller shaft :

The propeller. shaft transmits the power from the gear box to the final drive, and the dimensions of the propeller shaft are: $50,40 \mathrm{~mm}$ for the outer and inner diameters; respectively and $400 \mathrm{~mm}$ for the length.

- Final drive :

A set of two spiral bevel gears are used in order to change the direction of motion by 90 degrees.

c-Tested Tire:

The tested tire is mounted on the drum, and the frame is designed for testing different tires up to $1 \mathrm{~m}$ in diameter. The line of action of vertical load and towing resistance is passing through the tire centre. A special interface drum is to be used for each tire size.

\section{d-Tire Vertical Load:}

The vertical load on the tested tire is applied using different weights of predetermined values. The line of action of vertical load is passing through the tire centre. Because of constant speed test, the dynamic load is considered to be equal to the static one.

\section{2: The Measuring Equipment, and Data Acquisition:}

The measuring equipment, data recording and analysis system are designed for the measuring, reading, and analysis of the tests carried out using the soil bin. The measuring equipment include: torque transducer for measuring of the driving torque, displacement transducer for measuring of tire penetration (Sinkage), force transducer for measuring of the drawbar pull ( net traction ), and R.P.M counter to compute the number of tire revolutions. The data recording system stores the output data from the transducers in its internal memory and transfers it to a microcomputer for analysis. In this section, the principle of the measuring equipment and the data acquisition system are briefly highlighted:

\section{a- Torque Measurement:}

A wireless torque transducer MMS 9372- 005 with a maximum torque of 411 N.m is chosen to measure the driving torque of the tested tire. In this transducer; the torque transmitted causes twisting of the shaft which results in a variation of the resistance of the wire strain gauges mounted on the transducer shaft. Accordingly; the frequency change is measured and sent by a wireless transmitter. This frequency is sensed by the receiver and evaluated by the discriminator which gives an output voltage proportional to the applied torque.

\section{b-Displacement Transducer:}

This transducer measures the change of the tested tire level with respect to the track rail which is taken as a reference. It is an inductive coil displacement transducer with a linear variable differential transformer (LVDT) which provides a linear DC voltage proportional to the displacement (tire penetration).

\section{c-Force Transducer:}

The force transducer is to measure the drawbar pull (net traction). The load value is displayed on the front panel through an indicator or an optional 
analogue output voltage with a range from 0 to $10 \mathrm{~V} \mathrm{DC}$ maximum at full $\operatorname{load}(10 \mathrm{kN}$.).

\section{d-Revolution Measurement:}

A tachometer is used with a digital counter to measure the number of tested tire revolutions. An infra-red emitting diode and photo transistor sensor housed in a moulded package are used. The main principle of this transducer is that the phototransistor responds to the radiation from the diode when a reflective object is placed within the field. Accordingly the number of pulses resulting from the rotation of a disk with equally spaced holes is processed to give the number of revolutions.

\section{e- Data acquisition and Analysis:}

The output of the different sensors are recorded on a hybrid data acquisition and is processed by a microcomputer for analysis. The Tracker 3000 is supplied with 8 channel analogue input of either DC voltage or current and an internal memory capable of storing up to 462 scans of all 8 channels. Each of this channels can be of a different input type and can be individually scaled with a chosen engineering unit. The main specifications of the tracker 3000 are as follows:-

DC voltage

Current

Sample speed

$$
\begin{aligned}
: 1 \mathrm{~V} \mathrm{DC}, 10 \mathrm{~V} \mathrm{DC}, 100 \mathrm{mV} \mathrm{DC} . \\
: 4-20 \mathrm{~mA} . \\
: 32 \text { reading per channel per sec. }
\end{aligned}
$$

After each run of the single wheel traction tester, the output data from the transducers are stored in the internal memory of the data acquisition. These data are transmitted through a serial port of data acquisition via a cable to the computer serial port RS 232 .

\subsection{Testing Track :}

Referring to Fig.1, the testing track has the following dimensions: a total length of 20 meters, width of 2 meters and is capable of testing tire up to one - third from soil bin width (up to $66 \mathrm{~cm}$ tire width) to avoid the effect of boundary conditions, and the depth is 1.5 meters. Test speeds vary through a range of 0.2 to 2.5 meter per second. The testing track is designed such that there is six carriers of the three phase cable of the driving system which is rolling on the carrier. The distance between each carrier is $3 \mathrm{~m}$. These dimensions are chosen with the guide of the survey of the soil bins specifications available all over the world [1].

\subsection{Control Room :}

The control room contains the devices for power supply, control of motor speed, and a brake for towing resistance control in addition to the towing sensor (Force transducer).It contains also the microcomputer for data analysis.

\section{a- Towing Resistance Control :}

It controls the tester towing resistance (drawbar pull) which is changed by a hand brake. Referring to Fig. 3; the towing resistance control system is composed of the following:-

Body : Two longitudinal and parallel beams with cross member.

Hand brake: To control the towing resistance force.

Bearing and roller: To minimize the friction force. 
The pulley assembly: To transmit the tension force in a direction parallel to tension wire so, the reading of load ceil represents twice the value of the tension force .

Tension wire: It is connected between the single wheel traction tester and the towing resistance control .

Tension load cell: For measuring the towing resistance, and it is fixed between the towing resistance frame and the tension wire.

\section{b: Driving Motor Variable Speed Controller:}

An AC frequency converter is used for the variation of the motor speed by changing of AC voltage frequency. Accordingly the test speed is also changed.

\section{SOIL BIN MEASURED PARAMETERS:}

The measured parameters are: normal load, traction force, number of revolutions, actual distance, rolling resistance, drawbar pull, and tire penetration (sinkage). Using this measured parameters; the dynamic tireroad characteristics are evaluated. As an example; the following are evaluated experimentally using the constructed soil bin:-

- Tire - soil slip characteristics

- Drawbar pull - slip characteristics

\subsection{Tire - Soil Characteristics Evaluation:}

Using the previous measured parameters; calculation procedures are carried out for investigation of the following characteristics as a real example of tire

- soil slip characteristics. The conditions of the test carried out are:

- Tested soil : $\quad$ loose sand

- Tire : Radial ( 6 ply rating)

Size: $\quad 8.55-15$

inflation pressure : 1.5 , and 1 bar

The testing of tire in this work is carried at fixed normal vertical load, and different inflation pressures.

Testing Procedure:-

(1)-Determine the starting position of the test and a mark on the road test at the rigid wheel centre.

(2)-Start the acquisition by data logger

(3)-Run the vehicle and stop after a certain distance and put a mark at the rigid wheel centre

(4)-Measure the actual distance using a measuring tape.

(5)-At the same time the input torque, drawbar pull and the dynamic sinkage are recorded on the data acquisition system. "These data are processed using the computer, and the test results are plotted in Fig. 4, 5, \& 6.

(6)- To take care of the friction losses; a separate test run without load is carried out; from which the friction losses are estimated.

(7)- The compaction of the soil surface is performed using a special device designed with a roller of a given weight to produce the required soil compaction. The leveling is performed using a knife having the required depth. 


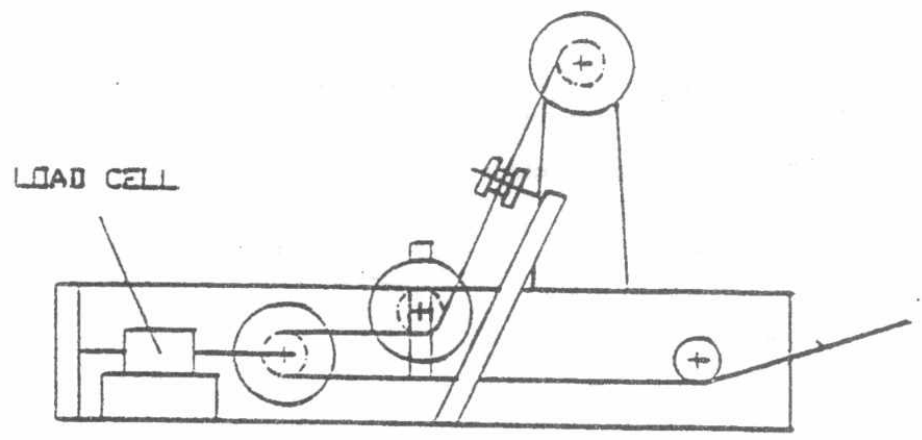

BRAKE DRUM

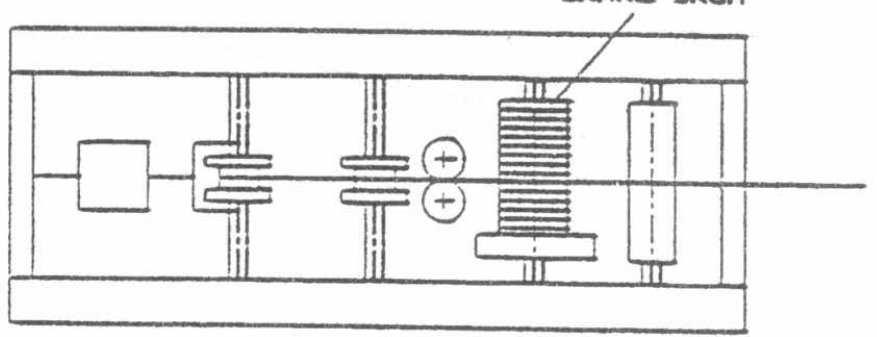

Fig.3 Towing resistance control

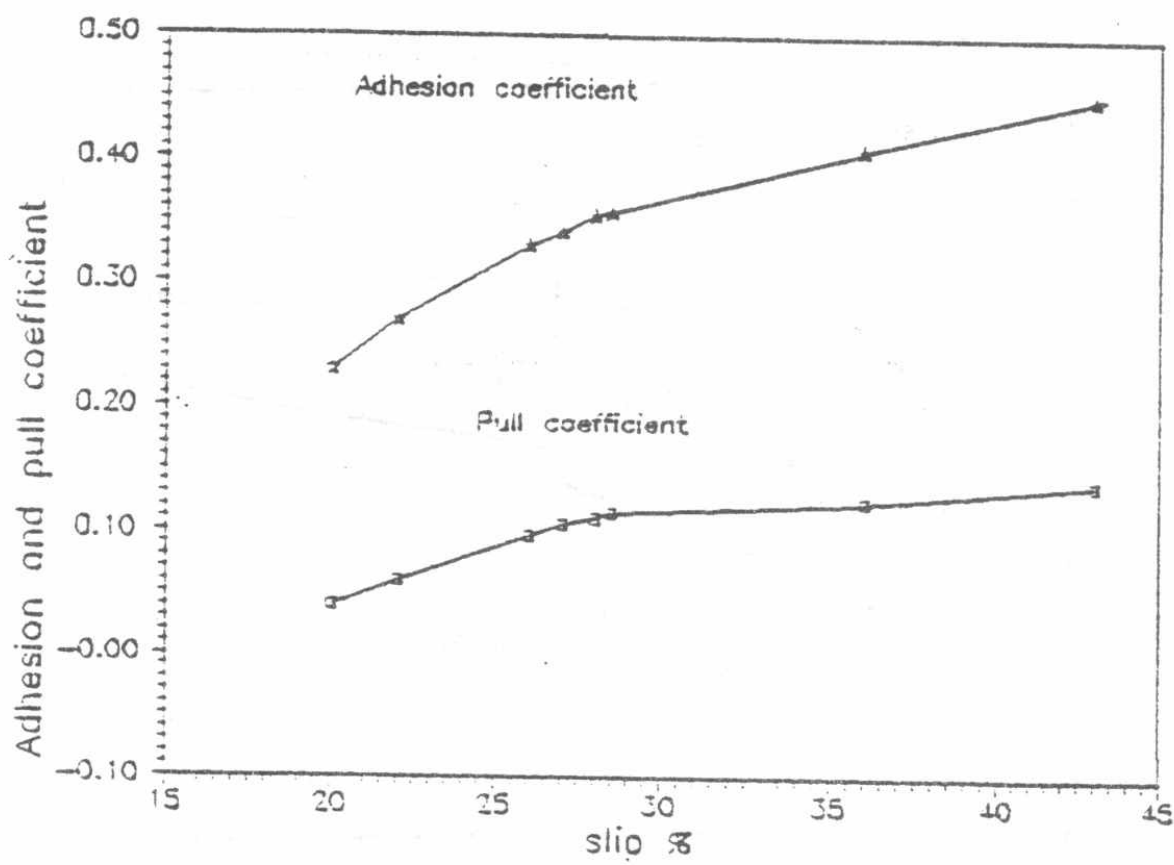

Fig.4 Relarionship berween adhesion coefficient, pull coefficient and slip \% on loose sand at inflation pressure 1.5 bar 


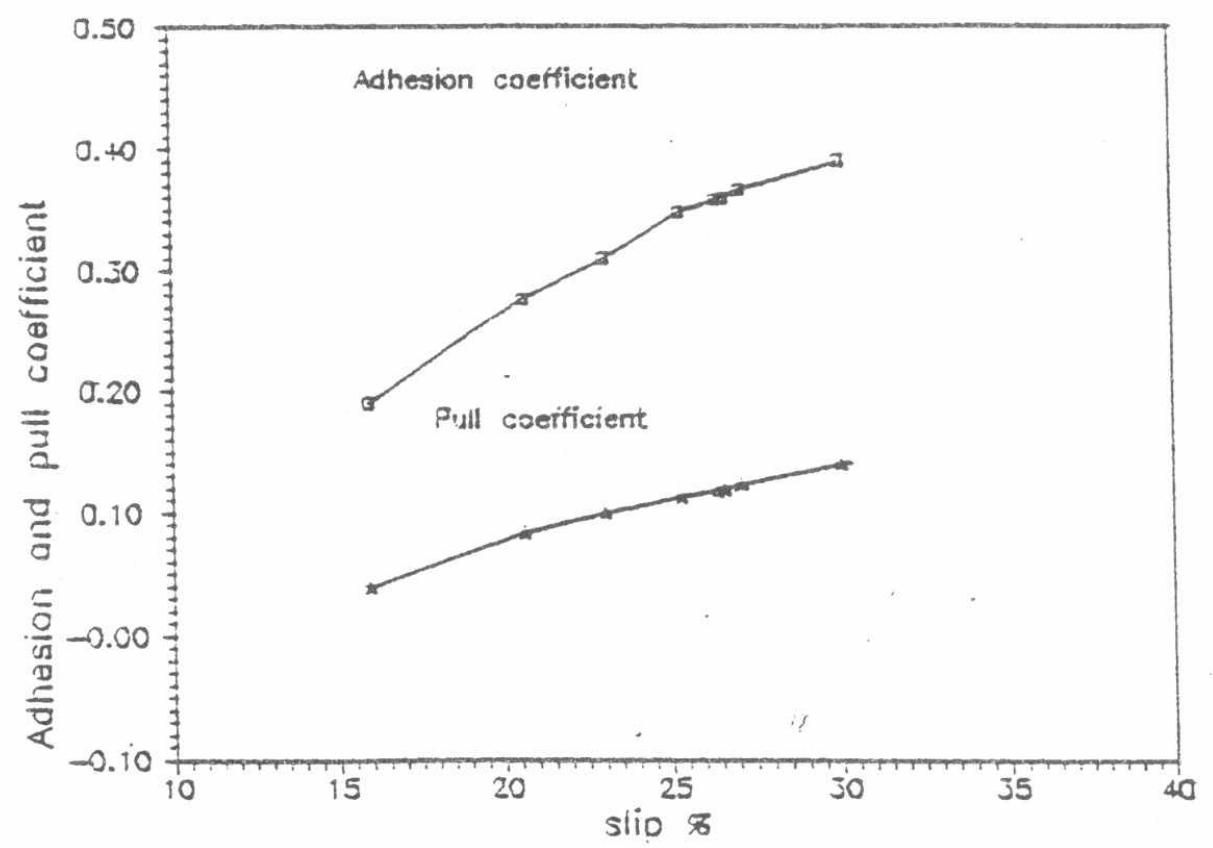

Fig.5 Relationship between adhesion coefficient, puil coefficient and slip $\%$ on loose sand at inflation pressure 1 bar

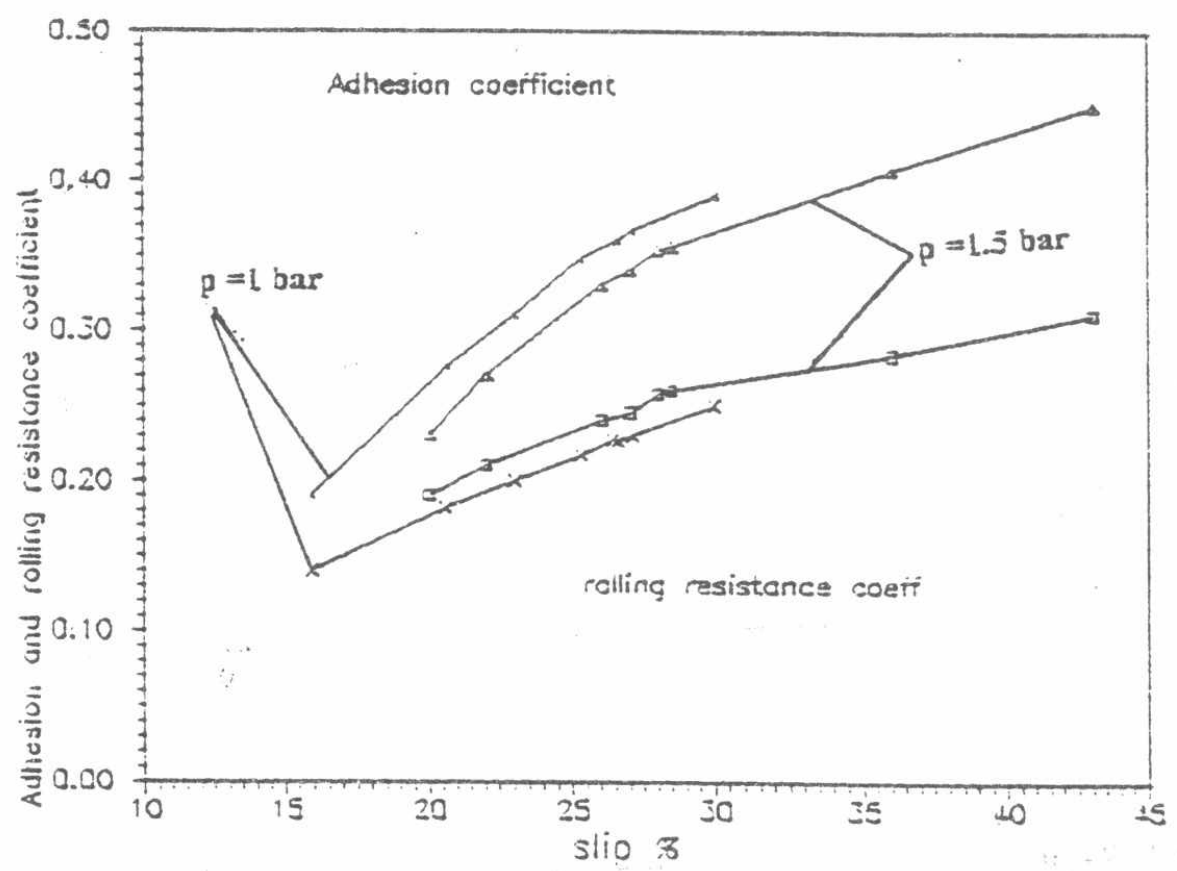

Fig.6 Relarionship between adhesion coefficient, rolling resistance coefficient and slip \% at different inflation pressure. 
Tabie 1 Soil bin instailations [1]

\begin{tabular}{|c|c|c|c|}
\hline & \multicolumn{3}{|c|}{ NUMBEA OF } \\
\hline & SOIL BINS & ENGINEERS & TECHNICLANS \\
\hline BELGIUM & ' & & \\
\hline Univ. Cath. Louvain & 3 & 1 & 2 \\
\hline CANADA & & & \\
\hline MeGiil Univ. & 3 & 4 & 3 \\
\hline $\begin{array}{l}\text { Univ. Saskatchewan } \\
\text { Versatile Noble Cultivators Co. }\end{array}$ & 1 & 18 & 5 \\
\hline Versatile Noble Custivators Co. & & & $\mathbf{z}$ \\
\hline $\begin{array}{l}\text { OENMAAK } \\
\text { ROYal Ver. \& Ag. Univ. }\end{array}$ & 1 & 1 & 1 \\
\hline FEDEFAL REPUBLC OF GEFMANY & & & \\
\hline Tech. Univ. of Munich & 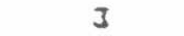 & 7 & 7 \\
\hline Univ. of German Forces & 2 & 10 & 3 \\
\hline FFANCE & & & \\
\hline Estab. Technique D'Angers & 2 & - & - \\
\hline JAPAN & & & \\
\hline Hokkaido Univ. & 3 & 12 & 2 \\
\hline Kvushu Univ. & 3 & 3 & $i$ \\
\hline Mie Univ. & 2 & 12 & 1 \\
\hline THE NETHEFLANDS & & & \\
\hline IMAG & 1 & 1 & $i$ \\
\hline Tecs. Univ. of Eindhoven & 2 & 3 & 3 \\
\hline POLAND & & & \\
\hline Inst. for Bidg. Mech. a Eiec:. & 2 & 3 & 2 \\
\hline Warsaw Agricuttural Univ. & 1 & $\mathbf{a}$ & 2 \\
\hline Warsaw Technical Univ. & $i$ & - & - \\
\hline PSOPLESS REPUEUC OF CHINA & & & \\
\hline Chiness Acad, of Ag. Macti y Science & 5 & 23 & 16 \\
\hline Jilin Univ. of Tecinnology & 4 & 17 & 9 \\
\hline Tracior Research Inse of China & 3 & 7 & 5 \\
\hline THAILAND & & & \\
\hline Asian inst. of Tecinology & 2 & 2 & 3 \\
\hline UNITED KINGDOM & & & \\
\hline Crantieid inst. of Tecinnology & 3 & 5 & $i$ \\
\hline National Inst. of Ag. Engineering & 3 & 2 & 2 \\
\hline Univ. of Newcastle Uoon Tyne & 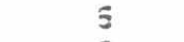 & 5 & 1 \\
\hline Royal Military College of Science & 3 & 2 & 2 \\
\hline Scotush Inst. of Ag. Engineering & 1 & 5 & 4 \\
\hline Transoort \& Road Research Lab. & 5 & 2 & $i$ \\
\hline UNITED STATES & & & \\
\hline Catergillar Tractor So. & 4 & 7 & 2 \\
\hline Oeere \& Comoany & 1 & 2 & $i$ \\
\hline Univ. of Illinais & 1 & - & - \\
\hline lowa Siate University & 1 & 4 & 1 \\
\hline Kansas Siate University & 1 & 2 & $i$ \\
\hline University of Kantucxy & $i$ & ; & 0.5 \\
\hline NTML USOA & 12 & 8 & 9 \\
\hline Nortin Carotina State Univ. & 3 & 3 & $i$ \\
\hline P.urdue University & 1 & 1 & 0.2 \\
\hline Virginia Palytecinic Inst. \& State U & 1 & 1 & $i$ \\
\hline
\end{tabular}


* It should be noticed that this test rig is designed only to measure the tire longitudinal forces. ${ }_{2}^{T}$ or the lateral and cornering forces, other test rig may be used.

\subsection{Analysis of the test results:}

From Fig.4, 5, \&6; the following can be seen:-

1. As the inflation pressure is decreased, the coefficient of adhesion is increased and the coeficient of rolling resistance is decreased. This is because when the inflation pressure is decreased, the contact area is increased leading to small specific pressure and smaller penetration. Accordingly adhesion coefficient is expected to be increased and rolling resistance is decreased.

The results show a qualitative agreement with the collected published work which gives a promise for using the test rig for more research applications .

\section{CONCLUSIONS:}

1-A soil bin is designed, produced, and assembeled. This constructed soil bin includes a single tire traction tester and the necessary measuring and recording instruments. Using this soil bin the, following can be measured and recorded dynamically for the tested tire and soil :

A.) the input driving torque

$B)$ the drawbar pull

C) the real speed

D) the prescribed revolutions of the tested tire

E) the dynamic sinkage

F) the vertical load

From the measured parameters; the following can be evaluated and analyzed:-

A) rolling resistance

B) the traction - slip characteristics

C) drawbar pull - slip characteristics

D) dynamic sinkage - load and inflation pressure

2-Using the construeted soil bin; a sample test has been carried out to evaluate the dynamic ive-road characteristics of (8.55-15) radial tire on a loose sand and the results showed a qualitative agreement with the available published work.

\section{REFERENCES:}

[1] Wismer, R.D. "Soil bin tacilities", Dene \& company technical center, U.S.A, 1986 . Fattah And Nicolas Skiadas, "Vehicle

[2] Raymond N. Yong, Ezzat A.Fattah And Nicolas Sk.achese traction inechamcs, 1984

3] Gzako, T.F." The influence of the inflation pressure on cross country performance", J.Terramechanics, Vol.11, No.3, 1974

4. "Passenger car tire performanc" SAE Handbook, 1986

[5] Shrmik upadhyaya, "Traction of low pressure pneumatic tires in deformable terrain", SAE 911862 , 1991

[6] Gzako, T.F. "The influence of the inflation pressure on cross country perfomance", J.Terramechanics, Vol.11 No.3, 1974

7] Wulfsohn. D, Upadhyaya S.K. and chancellor W.J.," Tractive 
characteristics of radial ply and bias ply tires", J.

Terramechanics , Vol.25, 1988

[8] Dwyer, M.J. "The tractive performance of a wide, low pressure tire compared with conventional tractor drive tires", J. Terramechanics, Vol.24, No. 3, 1987

[9] Dwyer, M.J. "Prediction of drawbar test performance", J.Terramechanics, Vol.24, No. 2, 1987 